\title{
Enfermedad de Castleman multicéntrica VHH-8 positivo en paciente inmunocompetente
}

\section{HHV-8 positive multicentric Castleman disease in immunocompetent patient}

\author{
Mayela Terrazos-Egoavil,' Rolando Vásquez-Alva, ${ }^{2}$ \\ Eloy Peña, ${ }^{3}$ Sonia Indacochea, ${ }^{3}$ Maria del Pilar Quiñones ${ }^{4}$
}

\author{
Terrazos-Egoavil M, Vásquez-Alva R, Peña $E$, \\ Indacochea S, Quiñones MdP. Enfermedad de \\ Castleman multicéntrica HHV-8 positivo en paciente \\ inmunocompetente. Rev Soc Peru Med Interna. 2019; \\ 32(3): $112-116$. \\ https://doi.org//0.36393/spmi.v32i3.478
}

\begin{abstract}
RESUMEN
Mujer de 60 años de edad que acudió al servicio de Emergencia por presentar sudoración nocturna, sensación de alza térmica, máculas eritematosas, edema de miembros inferiores y adenopatía cervical izquierda de cuatro semanas de evolución. Durante su hospitalización, presentó crecimiento de múltiples ganglios linfáticos en zonas cervical, axilar, mediastinal y retroperitoneal. Se tomó biopsia del ganglio cervical y fue diagnosticada como enfermedad de Castleman plasmocelular con positividad para VHH-8 por inmunohistqouímica. La paciente evolucionó con mal estado general, compromiso pulmonar, efusión pleural y falla respiratoria que requirió apoyo de ventilación mecánica; y, finalmente falleció.
\end{abstract}

Palabras Clave. linfoproliferativo, Castleman, virus herpes humano 8.

\begin{abstract}
A 60-year-old woman who came to the emergency room for having night sweats, sensation of fever, erythematous macular rash, lower limb edema and left cervical adenopathy for four weeks. During her hospitalization, she developed growth of multiple lymph nodes in cervical, axillary, mediastinal and retroperitoneal areas. Cervical node biopsy was taken and diagnosis of plasmocellular Castleman's disease with positivity for HHV-8 by immunohistochemical studies was done. The patient evolved with poor general condition, lung involvement, pleural effusion and respiratory failure that required mechanical ventilation support; and, finally, she died.
\end{abstract}

KEYWORDs: lymphoproliferative, Castleman, human herpes virus 8.

\section{INTRODUCCIÓN}

La enfermedad de Castleman (EC) es un transtorno linfoproliferativo policlonal denominada también hiperplasia nodular gigante o hiperplasia linfoide angiofolicular. Presenta dos formas clínicas conocidas como EC localizada o unicéntrica (ECU) y EC

I Médico residente de Medicina interna. Departamento de Medicina Interna, Hospital Essalud Edgardo Rebagliati Martins (HEERM), Lima.

2 Médico internista y emergenciólogo. Departamento de Emergencia, HEERM. Facultad de Medicina, Universidad Nacional Mayor de San Marcos, Lima.

3 Médico internista. Departamento de Medicina Interna, HEERM, Lima.

4 Médico anatomo-patólogo. Departamento de Patología, HEERM, Lima multicéntrica (ECM). El estudio histopatológico es fundamental para el diagnóstico y permite clasificarlo en sus variantes hialinovascular, plasmocelular y mixto. ${ }^{1}$

Benjamín Castleman describió, en 1956, una serie de casos de hiperplasia ganglionar mediastinal localizada en las que destacaba una proliferación de folículos linfoides con centros germinales involutivos, asociados a hiperplasia vascular y endotelial en las áreas intra e interfolicular. ${ }^{2}$ Esta entidad se vio asociada a anemia hipocrómica, hipergammaglobulinemia y plasmocitosis en médula ósea. En 1969, se describió una variante rica en células plasmáticas y en 1972 se estableció las diferencias entre el "tipo hialinovascular" clásicamente descrito y el "tipo de células plasmáticas", que era menos común y se asociaba con signos y/o síntomas sistémicos. Posteriormente, se describió linfadenopatías multicéntricas asociadas con los síntomas constitucionales y características histológicas similares a los tipos ECU. Diez años más tarde se reportó un nuevo tipo de virus herpes humano asociado con el sarcoma de Kaposi, el virus del herpes humano del tipo 8 (VHH-8). Posteriormente, el VHH-8 se identificó en los linfomas primarios de efusiones y en la ECM, particularmente en individuos positivos al 
virus de la inmunodeficiencia humana $(\mathrm{VIH})$, mientras que la asociación a VIH negativo es poco conocida. ${ }^{3}$

\section{PRESENTACIÓN DEL CASO}

Mujer de 60 años de edad, natural de Cusco y procedente de Lima, oficinista, sin antecedentes patológicos. Ccon historia de cuatro semanas, caracterizada por sudoración nocturna, fiebre, debilidad general a predominio de miembros inferiores, hiporexia, lesiones dérmicas tipo eritema macular en miembros inferiores y adenopatías axilares y cervicales izquierdas palpables. Con una biopsia reportada como infiltrado de células plasmáticas.

\section{Examen físico}

Peso $55 \mathrm{~kg}$, temperatura $38^{\circ} \mathrm{C}$, presión arterial $120 / 60 \mathrm{mmHg}$, frecuencia cardiaca $75 / \mathrm{min}$, frecuencia respiratoria 20/min, saturación de $\mathrm{O}_{2} 98 \%$. Lúcida, con palidez marcada, mucosa oral poco hidratada. Cuello: se palpa adenopatía cervical izquierda de 2 x $1 \mathrm{~cm}$ y axilares múltiples. Pulmones: crepitantes en base de hemitórax derecho. Corazón: ruidos cardíacos rítmicos, no soplos. Abdomen: ruidos hidroaéreos presentes, blando depresible, leve dolor a la palpación en hipocondrio derecho, hígado palpable a $2 \mathrm{~cm}$ por debajo del reborde costal derecho. Edema leve a moderado en miembros inferiores con lesiones dérmicas tipo eritema macular.

\section{Exámenes auxiliares}

Hb 6 g/dL; VCM 86 fL; HCM 26 fL; leucocitos 5000 cél/ $\mathrm{mm}^{3}$; plaquetas $275000 / \mathrm{mm}^{3}$. Glucosa $123 \mathrm{mg} / \mathrm{dL}$; urea $21 \mathrm{mg} / \mathrm{dL}$; creatinina $0,7 \mathrm{mg} / \mathrm{dL}$; proteínas totales $7,7 \mathrm{~g} / \mathrm{dL}$, albúmina 2,33 g/dL, bilirrubina total $0,5 \mathrm{mg} / \mathrm{dL}$, bilirrubina directa $0,14 \mathrm{mg} / \mathrm{dL}$. TGO $27 \mathrm{U} / \mathrm{L}$; TGP $34 \mathrm{U} / \mathrm{L}$, VSG $35 \mathrm{~mm} / \mathrm{h}$; PCR 18,0 mg/dL.

TORCH, RPR, anticuerpos antinucleares, Elisa VIH y anticuerpo antineutrófilo citoplasmático negativos, $\beta 2$-microglobulina 4,9 mg/dL. Marcadores tumorales (CEA/AFP/CA125/CA19.9) negativos; HTLV 1-2, set de hepatitis, cultivos para Mycobacterium tuberculosis, hemocultivos y urocultivos negativos.

\section{TOMOgRAFíAS de CUELLO, TÓRAX, ABDOMEN Y PELVIS CON CONTRASTE}

Adenopatías cervicales en el grupo IIa de ambos lados de hasta $1,1 \mathrm{~cm}$, adenopatía de $1,3 \mathrm{~cm}$ en el grupo III izquierdo. Adenopatía de $1,3 \mathrm{~cm}$ x 1,2 cm adyacente al lóbulo izquierdo de la tiroides. Mediastino con conglomerado ganglionar prevascular izquierdo, pretraqueal retrocavo, subcarinal y en la ventana aortopulmonar. Ganglios con hilio graso en ambas axilas; el mayor, de $2,4 \mathrm{~cm}$ en el lado izquierdo.
Derrame pleural a predominio derecho. Esplenomegalia moderada, de $13 \times 6 \mathrm{~cm}$. Hígado de $19 \mathrm{~cm}$, parénquima homogéneo. Retroperitoneo con conglomerado ganglionar paraaórtico infrarrenal de 2,9 x 1,7 cm, adenopatías retrocrurales bilaterales e intercavoaórtica de hasta 1,1 $\mathrm{cm}$. Adenopatías en ambas cadenas ilíacos internas, la de mayor tamaño de $1,4 \mathrm{~cm}$ en el lado izquierdo. Adenopatías en ilíaca externa derecha de $1,8 \mathrm{~cm}$ y adenopatía ilíaca externa izquierda de 2,0 cm. (Figura 1).
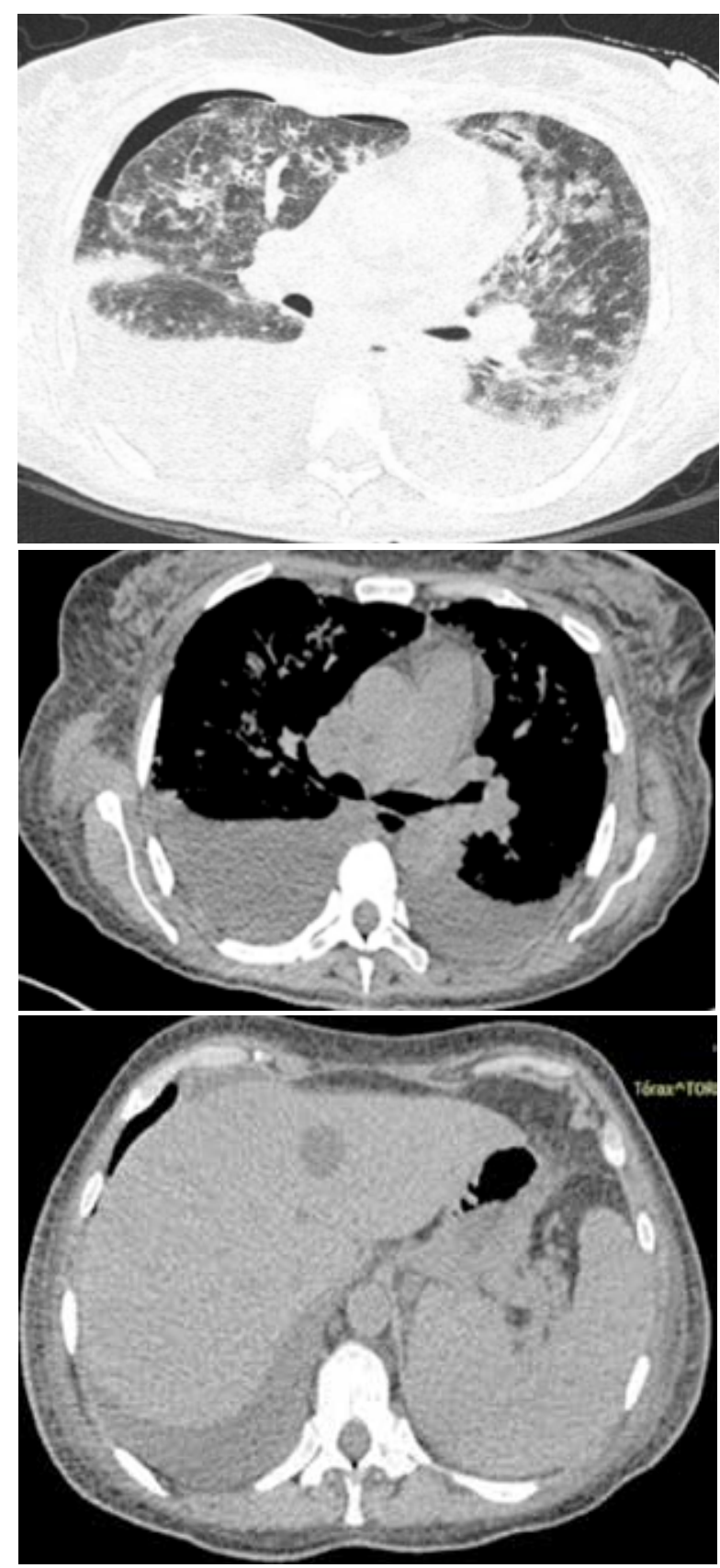

Figura I. 

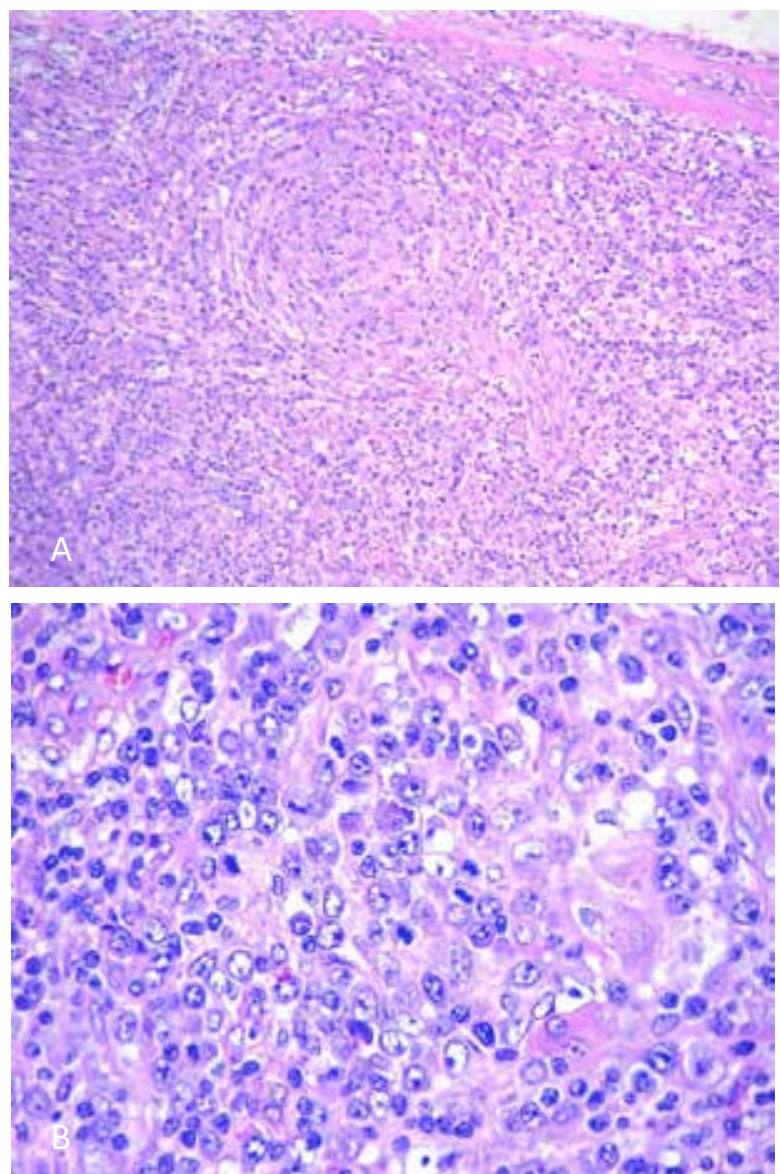

Figura 32 Ganglio linfático. A) Distorsión de su arquitectura, formaciones nodulares en lollipop, (IOX). B) Células plasmáticas y plasmablastos con numerosas mitosis (20X).

\section{ECOGRAFIA de CUELLO}

Quiste coloide en el lóbulo tiroideo derecho de $2 \mathrm{~mm}$. Múltiples adenopatías en los diferentes grupos ganglionares cervicales, la de mayor tamaño de $19 \mathrm{~mm}$.

\section{ECOCARDIOGRAMA}

Fracción de eyección $60 \%$, no valvulopatías, hipertensión pulmonar leve a moderada.

\section{BIOPSIA DE HUESO}

Hipercelularidad leve para la edad (55\%-60\%) con relación mieloide/eritroide 2,5/1. No evidencia de infiltración linfomatosa o de otra naturaleza. CD5

Figura 3. Inmunohistoquímica. A) CDI38 negativa en los plasmablastos (20X). B) CD38 positiva en los plasmablastos (20X). C) La tinción para HHV-8 es positiva en las células células neoplásicas (IOX).D) El índice de proliferación con Ki67 es del $80 \%$ en las células neoplásicas (IOX).
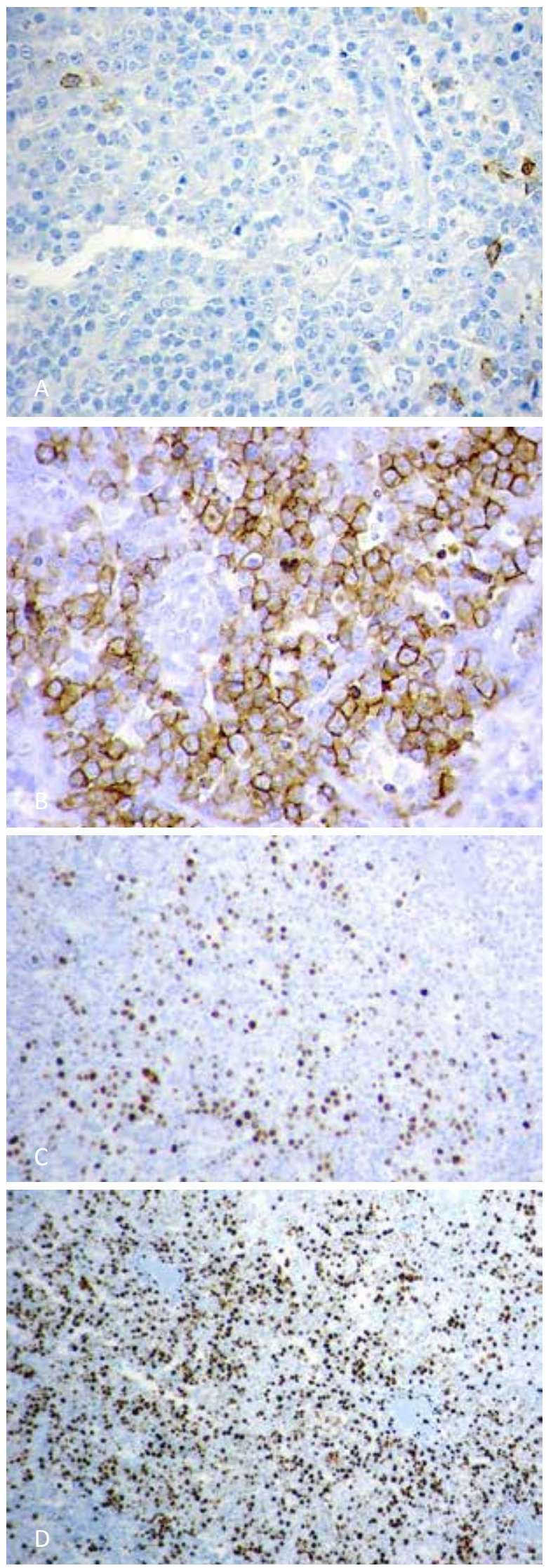
positivo $5 \%$ en linfocitos $\mathrm{B}$; $\mathrm{CD} 3$ positivo en linfocitos $\mathrm{T}$ $25 \%$; CD138 positivo en células plasmáticas $15 \%$. Conclusión: dos agregados linfoides de significado no precisado, probablemente reactivos; plasmocitosis de distribución intersticial.

\section{BIOPSIA DE GANGLIO CERVICAL}

Folículos linfoides alterados describiendo la típica imagen en 'paleta' (lollipop) (Figura 2A), resaltando una proliferación de células plasmáticas, algunas maduras y otras con morfología plasmablástica dispuestas dentro y fuera de los folículos linfoides, con alto índice de proliferación, describiendo un patrón concéntrico en tela de cebolla (Figura 2B).

\section{INMUNOHISTOQUÍMICA}

Hiperplasia linfoide atípica. Las inmunotinciones realizadas para CD3, CD20, CD23, CD30 y Ki67 no revelaron proliferaciones neoplásicas linfoides. Cadenas kappa y lambda no evidencia restricción de cadenas ligeras. Se observó que la mayor parte de los plasmablastos fueron positivos para CD38 y negativos para CD138 (Figura 3A), lo cual sugirió una clona aberrante.

El HHV8 fue positivo (Figura 3B) consistente con EC variedad plasmocelular. Dado el elevado índice de proliferación en los plasmablastos (Figura a) se planteó la posibilidad de un inminente viraje a un linfoma plasmablástico.

\section{Evolución}

La paciente permaneció en el servicio de Medicina interna y, posteriormente, en el de Hematología, empezó tratamiento con ganciclovir y rituximab. Evolucionó con deterioro respiratorio, efusión pleural bilateral y disnea a moderados esfuerzos. Posteriormente, se inició poliquimioterapia con ciclofosfamida, vincristina y prednisona más rituximab. La paciente presentó neumonía e insuficiencia respiratoria pasando a la Unidad de Cuidados Intensivos donde se instaló ventilación mecánica; y, falleció, posteriormente.

\section{DISCUSIÓN}

Se presenta el caso de una paciente de sexo femenino con hiporexia, numerosas adenopatías mediastinales, supraclaviculares y cervical en donde le realizaron biopsia cuyo informe de revisión de láminas fue reportado como compatible con EC variante de células plasmáticas, ECM/VHH-8+, Elisa VIH negativo.
La ECM se presenta a mayor edad que la forma localizada, con una mediana de 60 años, tal como el caso presentado. ${ }^{8}$ Se estima que la incidencia aproximada de la EC es desconocida. En estudios de cohortes al extraer información en una base de datos se ha estimado una incidencia aproximada de 21 casos por millón de habitantes en EE. UU. ${ }^{4}$

La ECU es asintomático en el $78 \%$ de los pacientes, presenta clínica de evolución más lenta, caracterizada por la aparición de nódulos ganglionares cervicales generalmente asintomático, salvo por compresión, con histología típica hialino-vascular, describiéndose que la cirugía con exéresis del tumor casi siempre es curativa. ${ }^{5}$

La ECM es un trastorno linfoproliferativo sistémico, menos de un $10 \%$ son asintomáticos. Se presenta con fiebre, sudoración nocturna, pérdida de peso, debilidad o fatiga, hepatoesplenomegalia, linfadenopatías, anemia, hipoalbuminemia e hipergammaglobulinemia, así como edema, efusiones, trastornos de la piel (exantema, hemangioma, y pénfigo) y alteraciones neurológicas. ${ }^{6}$ La mayoría de estos síntomas estuvieron presentes en nuestra paciente. Esto se debe a Las alteraciones histológicas en los ganglios linfáticos con proliferación linfovascular que se deben principalmente a la elevación de las interleucinas 6 viral (IL-6 V) y 1 (IL-1), así como la presencia del VHH-8, todo lo cual determinaría en los ganglios una hiperplasia centrogerminal e incremento de los inmunoblastos y de la vascularidad?

La ECM comprende dos subgrupos, la ECM asociada a VHH-8 (ECM/VHH-8) y la ECM idiopática (ECMi), que no está asociada con ningún agente etiológico conocido. ${ }^{8}$ La ECM/VHH-8 se subdivide a su vez en VIH (+) y VIH (-), esta última sin una incidencia conocida. Existe también presentaciones específicas de la EC como pénfigo paraneoplásico, síndrome POEMS, TAFRO y linfohistiocitosis hemofagocítica. ${ }^{9}$

El VHH-8 es un agente causal de ECM. La infección por el virus de inmunodeficiencia humana (VIH) u otra causa de inmunodeficiencia permiten que el VHH-8 escape del control inmune del hospedero, se replique en los plasmoblastos de los ganglios linfáticos y favorezca la liberación de citocinas que provocan los síntomas clínicos y hallazgos patológicos. ${ }^{9}$

El VHH-8 infecta las células B y los plasmoblastos, que pueden detectarse mediante tinción inmunohistoquímica del ganglio linfático para el antígeno nuclear asociado. Destaca el papel crítico de las células B en la ECM/ 
VHH-8, su depleción con rituximab es una terapia altamente efectiva. Los niveles de células $\mathrm{T}$ periféricas, que incluyen las células CD81 T de memoria efectoras polifuncionales, también se han asociado con la patogénesis de la ECM/VHH-8. ${ }^{10}$

En la ECM/VHH-8 y VIH negativos, la presentación clínica es similar a la ECM VIH positiva, con síntomas sistémicos importantes, linfadenopatía asimétrica y esplenomegalia, el alto nivel de PCR, hipoalbuminemia, hipergammaglobulinemia. La carga viral del VHH-8 es alta, y el virus se puede detectar en los ganglios linfáticos con tinción LANA-1 además de los hallazgos clásicos de la ECM (centros germinales agotados, zonas de manto expandidas, infiltración prominente de células plasmáticas en la región interfolicular y vascular hiperplasia). La presencia de sarcoma de Kaposi es frecuente en pacientes VIH positivo, así como el mayor riesgo de linfoma relacionado con VHH- $8 .{ }^{9}$

Este tipo de subclasificación del ECM es sensible y responde al rituximab y al régimen basado en etopósido, pero la recaída es frecuente y requiere una estrecha monitorización. ${ }^{10}$

Para confirmar el diagnóstico se requiere de la biopsia del nódulo linfático, que es la prueba definitiva de la EC. Se observa el patrón hialino-vascular o la infiltración de células plasmáticas según la variedad. Se practica inmunohistoquímica para antígenos virales tipo VHH-8 que se encuentra en $10 \%$ a $30 \%$ de las células linfoides de la zona del manto que tienen una morfología inmunoblástica. ${ }^{9}$

La inmunohistoquímica para VHH-8 LANA-1 en los ganglios linfáticos es el estándar de oro para la detección del VHH-8 en ECM. La medición de la carga viral de VHH-8 mediante la reacción en cadena de la polimerasa (PCR) de la sangre durante la enfermedad activa también puede ser útil para determinar el estado de VHH-8. Los títulos serológicos para VHH-8 tienen una utilidad clínica limitada y no debe realizarse. ${ }^{10}$

No existe un tratamiento estándar para ECM/VHH-8; proviene de revisiones sistemáticas de la literatura debido a la rara presentación de esta enfermedad, el tratamiento en la práctica clínica varía. ${ }^{11}$ Depende primero de si el paciente es VIH/VHH-8 positivo, y luego en la agresividad clínica de la enfermedad.

En pacientes con VIH-/VHH-8+ y sintomáticos sin evidencia de insuficiencia orgánica, se sugiere el uso de la inmunoterapia sola (tocilizumab, siltuximab, rituximab).
Para los pacientes con evidencia de insuficiencia orgánica o mal estado general debida a la enfermedad, se sugiere terapia de combinación con rituximab más quimioterapia tales como CHOP (ciclofosfamida, doxorrubicina, vincristina, prednisona) o CVAD (ciclofosfamida, vincristina, doxorrubicina y dexametasona).

Enpacientes VIH+/VHH-8+, se sugiere una combinación de ganciclovir más la terapia antirretroviral (TAR). ${ }^{8}$

Nuestro paciente recibió tratamiento con ganciclovir y rituximab, evolucionó con deterioro respiratorio, efusión pleural bilateral y disnea a moderados esfuerzos. Posteriormente, se inició poliquimioterapia con ciclofosfamida, vincristina y prednisona más rituximab. La paciente ingresó a la unidad de Cuidados Intensivos en ventilación mecánica y, posteriormente, falleció.

\section{REFERENCIAS BIBLIOGRÁFICAS}

I. Castleman B, Iverson L, Mendez V. Localized mediastinal lymphnode hyperplasia resembling thymoma. NCBI [Internet]. 1956 [citado 6 abril 2019];(4):822-30. URL disponible en: https://www.ncbi.nlm.nih. gov/pubmed/I3356266

2. Keller AR, Hochholzer L, Castleman B. Hyaline-vascular and plamacells types of gyant lymph node hyperplasia of the mediastinum and other locations. Cancer. 1972;29:670-683.

3. Kim JE, Kim CJ, Park IA, Kim WH, Seo JW, Jang JJ et al. Clinicopathologic study of Castleman's disease in Korea. J Korean Med Sci. 2000; 15:393-398.

4. González García A, Moreno Cobo MA, Patier de la Peña JL. Diagnóstico y tratamiento actual de la enfermedad de Castleman. Rev Clin Esp. 2016;216:146-156.

5. Mehra MCN, Stellhorn RA, Vermeulen J, Desai A, Munshi NC .Use of a claims database to characterize and estimate the incidence of Castleman's disease. ASH Annual Meeting Abstracts. 20I2;120:4253.

6. Hoffmann C, Schmid $H$, Müller $M$, et al. Un mejor resultado con rituximab en pacientes con VIH enfermedad de Castleman multicéntrica asociada. Sangre. 20I I; I I8: 3499.

7. Páez P, Rosado M, Barón O. Enfermedad de Castleman, "La gran imitadora". Acta Med Colomb. 2017;42(4):247.

8. Bowne WB, Lewis JJ, Filippa DA, Niesvizky R, Brooks AD, Burt ME, et al. The management of unicentric and multicentric Castleman disease: a report of 16 cases and a review of the literature. Cancer. 1999;85:706-17.

9. van Rhee F, Greenway A. Treatment of idiopathic Castleman disease [Internet]. 3rd ed. California: Elsevier;2019 [cited 9 Junio 2019]. URL disponible en: https://doi.org//0.1016/j.hoc.2017.09.008

10. Robinson Jr D, Reynolds M, Casper C. Clinical epidemiology and treatment patterns of patients with. $\mathrm{Br} J$ Haematol [Internet]. 20|4;(I65):39-48. URL disponible en: doi.org//0. I I I //bjh. I27/7|

II. Szalat R, Munshi N. Diagnosis of Castleman Disease. Elsevier [Internet]. 2018 [citado 10 Abril 2019];(32):53-64. URL disponible en: https://doi.org//0.1016/j.hoc.2017.09.005

CORRESPONDENCIA: Mayela Terrazos-Egoavil

racaelifa@hotmail.com

FECHA DE RECEPCIÓN: 4 de setiembre de 2019.

FECHA DE ACEPTACIÓN: 20 de setiembre de 2019. 